\title{
Influencing factors on time of breastfeeding initiation among a national representative sample of women in India
}

\author{
Maria Sandor ${ }^{1}$, Koustuv Dalal $^{1,2^{*}}$ \\ ${ }^{1}$ School of Life Sciences, University of Skövde, Skövde, Sweden \\ ${ }^{2}$ School of Health and Medical Science, Örebro University, Örebro, Sweden; \\ *Corresponding Author: koustuv2010@hotmail.com
}

Received 18 November 2013; revised 18 December 2013; accepted 25 December 2013

Copyright (C 2013 Maria Sandor, Koustuv Dalal. This is an open access article distributed under the Creative Commons Attribution License, which permits unrestricted use, distribution, and reproduction in any medium, provided the original work is properly cited.

\begin{abstract}
Breastfeeding is seen as vital for mother and child and therefore is of great public health concern. Early initiation of breastfeeding within one hour of delivery is important as it reduces neonatal mortality. Increasing our understanding of barriers and reasons for not commencing early breastfeeding is important to improve strategies and conditions to overcome such barriers. Hence, the present study aimed to investigate factors influencing time of breastfeeding among women in India, focusing on health care utilisation related issues and partner behaviour. Data from the Ministry of Health and Family Welfare of the Government of India's National Family Health Survey (NFHS) from 2005-2006 (NFHS-3) have been used in this study. Breastfeeding for the latest child was considered in the study. A total of 35,795 female respondents are included in this study. Chi square test and adjusted logistic regression analysis were used. Among all 35,795 women in the study, a total of $31.1 \%$ initiated breastfeeding within one hour and $68.6 \%$ initiated breastfeeding within the first week. Educational level, economic status and women's caste or tribe, place of delivery, prenatal visits to health care facilities and assistance during delivery as well as partner's controlling and violent behavior are important factors influencing time of initiation of breastfeeding. It is evident that policy makers need to ensure that all health professionals support and promote early breastfeeding initiation. It is also important to promote deliveries in hospitals and other healthcare facilities as they may increase early initiation. Fur-
\end{abstract}

thermore, it is fundamental that efforts are intensified for girls and women to obtain education to increase women's empowerment and improved gender equality.

Keywords: Breastfeeding; Socioeconomic; Partner Violence; India

\section{INTRODUCTION}

Breastfeeding has an important role in public health due to its numerous health benefits for children and mothers [1,2], for example, there is convincing evidence that breastfeeding has beneficial effects in the prevention of gastrointestinal infections, including diarrhoea [3-6], and otitis media $[7,8]$. Furthermore, studies have shown that it has proven beneficial for mothers in reducing risk of rheumatoid arthritis [9] as well as, to a certain extent, reducing risk of pre-menopausal breast cancer [10] and ovarian cancer [11-14].

It has been demonstrated that infants born in a particular ward where time of first suckling was earlier generated a higher incidence of breastfeeding [15]. Moreover, the first breast milk contains colostrum, which especially protects the infant against infections. A study carried out in Ghana demonstrated an increased risk of neonatal mortality if initiation of breastfeeding was delayed from 1 hour to day 7 [16]. The same study also showed that late initiation, defined as after day 1 , was related with an increase of risk of neonatal death by 2.4 times [16]. Similar results were demonstrated in a study in Nepal, where a higher mortality was associated with later initiation of breastfeeding, defined as after 24 hours, compared to early initiation, defined as before 24 hours [17]. For this reason, WHO recommends breastfeeding to be initiated within 1 hour after giving birth [18]. Hence 
promoting and providing possibilities to initiate early breastfeeding is vital to reduce the risk of ill health for the infant. In India, according to statistics from International Baby Food Action Network (IBFAN), 24.5\% mother initiated breastfeeding within 1 hour [19]. It is worthwhile to mention here that the neonatal mortality rate in India is 43 per 1000 live births, in comparison with for example Australia, which has 1 per 1000 live births [18].

Utilisation of health care, and particularly maternal health care, is vital for the health of mothers and infants $[20,21]$. It is important for pregnant women to receive antenatal care; the WHO recommends at least four visits or assessments of antenatal care [18]. Furthermore, it is highly encouraged that delivery occurs in a suitable and hygienic environment under the supervision of health professionals. As such, to reduce health risk of mothers and infants it is important that they receive sufficient care before, during and after delivery, including neonatal care such as breastfeeding. Unfortunately, there is a lack of utilisation of health care facilities in India [22]. Reasons for this vary but too far a distance to a facility, long waiting time and poor quality of healthcare are some of the reasons that have been found to impact upon this [23]. As such, availability of health care services for women giving birth is limited, especially for women living in rural areas, and may impact on possibilities of early initiation of breastfeeding.

Partner behaviours, such as controlling behaviour or violent behaviour, have several negative effects on women's health behaviour such as contraceptive use, sanity, reproductive health issues and neonatal care [24,25]. Therefore, it may have a negative effect on breastfeeding initiation. There is a lack of studies focusing on controlling behaviour and the effect it may have on breastfeeding initiation. However, studies have shown that experience of abuse and violence affects breastfeeding [26-28]. For example, Lau and Chan [28] found that women who have not experienced violence from a partner during pregnancy were more likely to initiate breastfeeding compared to women who had experience of partner violence. Regrettably, prevalence of domestic violence or gender-based violence is quite high in India [29] and there is a fairly high social acceptance of gender-based violence [30]. It is therefore of importance to investigate what influence partner's behaviour may have on breastfeeding initiation. Several studies have tried to explore influencing factors for the initiation of breastfeeding in different country contexts. In India, there is no such study using national representative samples.

As early initiation of breastfeeding is vital for the health of the child understanding barriers and reasons for not commencing early breastfeeding are important to increase our knowledge of these barriers and hence im- prove conditions and strategies to overcome these barriers. Early initiation of breastfeeding is also a contributing factor towards the achievement of the Millennium Development Goal of increased levels of child survival. WHO not only highlights the importance of increasing early initiation of breastfeeding but question why it has not received more attention [31]. Hence, the current study aims to examine factors influencing time of initiation of breastfeeding among women in India, using nationally representative samples. Health care utilisation related issues and partner behaviour were emphasized as predicting factors of breastfeeding initiation.

\section{METHOD}

Data from the Ministry of Health and Family Welfare of the Governments of India's National Family Health Survey (NFHS) from 2005-2006 (NFHS-3) has been used in this study. A total of 124,385 women between the age of 15 - 49 from all 29 member states of India participated in the NFHS. In the present study a total of 35,795 female respondents are included. This is based on the number of women who reported that they had breastfed at least one child and represent $29 \%$ of the overall participating women in the NFHS.

\subsection{NFHS Questionnaire}

The questionnaire being used in the NFHS is focused upon information on health and family welfare issues. Data was collected via three different questionnaires, one for the household, one for women and one for men. It is the questionnaire for women that form the basis for the current study. The questionnaire for women contained details on background and demographics, reproductive history, family planning methods, fertility preferences, antenatal and delivery care, child care and nutrition, child and adult mortality, information regarding STDs, AIDS, marriage, sexual behaviour, empowerment and social indicators, domestic violence, use of health care. In regards of the present study, attention has been given to the sections on antenatal and delivery care, child care and nutrition and domestic violence.

\subsection{NFHS Data Collection and Sampling}

The data for the NFHS-3 was collected between December 2005 and August 2006. Sampling for the NFHS3 was based on the sampling design of probability proportional to size (PPS). The initial sample size was determined to comprise 1500 completed interviews in states with a population less than 5 million (based on the 2001 Census), 3000 completed interviews in states with 5 to 30 million and finally 4000 completed interviews in states with a population over 30 million. The only exception to this was in the largest state, Uttar Pradesh, where 
a fixed number of 10,000 completed interviews was determined. All of the completed interviews were with ever-married women (i.e. married at any time in their lives) between the age 15 and 49. In the rural areas, a two stage sample design was conducted where the first stage consisted of selecting Primary Sampling Units (PSUs), villages, using PPS and the second stage consisted of systematic selection of households within each PSU. In the urban areas a three-stage sample design was used instead due to larger wards. The first step consisted of selecting Primary Sampling Units (PSUs), municipal wards, using PPS, the second step involved random selection of census enumeration blocks (CEB) and finally the third stage consisted of randomly selecting households within each CEB. For more information on the details of the sampling design used in the NFHS-3 can be found in the final report of the NFHS-3 [32]. The NFHS3 fieldwork was conducted by 18 research organizations between December 2005 and August 2006.

\subsection{Dependent Variables}

Time of breastfeeding initiation was defined as when after birth the women commenced breastfeeding. Breastfeeding was initiated immediately (i.e. within one hour of the delivery) within 24 hours (i.e. after one hour to 24 hours) of the delivery or after 24 hours of the delivery. Breastfeeding for the latest child was included in the study.

\subsection{Independent Variables}

Demographic factors were defined as age, urban or rural residency, economic status, educational level, religion, caste or tribe. Age was categorized into seven groups (15 - 19, 20 - 24, 25 - 29, 30 - 34, 35 - 39, 40 - 44, 45 - 49; education was categorized into four groups (no education, primary, secondary, higher); religion was grouped into Hindu, Muslim, Christian and Others; and economic status was measured as the quintiles of all household economic assets and grouped into poorest, poorer, middle, richer and richest [23]. In India there are difference racial and ethnic minorities. Some of these groups are classified into scheduled caste, scheduled tribe, and other backward class (OBC) by the Indian Government as they are socially and economically disadvantaged. Belonging to one of these three categories grants the opportunity of positive discrimination in areas of education and employment [33].

Health care utilisation factors included place of delivery, pre-natal visit and delivery assistance. Place of delivery included home delivery, public hospital and private hospital delivery. Pre-natal visits of the respondents were categorized into three groups: 1) visit to doctor; 2) visit to nurse/midwife/auxiliary nurse midwife (ANM)/ lady health visitor (LHV); and 3) visit to trained birth attendants (TBA)/health persons (IIPS, 2007). Assistance during delivery was provided by 1) doctor; 2) nurse/ midwife/auxiliary nurse midwife (ANM)/lady health visitor (LHV); 3) trained birth attendants (TBA)/health persons; and 4) by the relatives or friends. These variables had yes/no answering options.

Husband's/partner's controlling behaviour was measured by six variables: Husband jealous if talking with other men; Husband accuses her of unfaithfulness; Does not permit her to meet her girlfriends; Husband tries to limit her contact with family; Husband insists on knowing where she is; and Husband doesn't trust her with money. Violence against women was measured by whether respondent had experienced (during conjugal life) any emotional, physical and sexual violence by the husband/partner. These variables had yes/no answering options.

\subsection{Statistical Analyses}

The proportions and Chi-square tests were performed to explore the cross-relationships between dependent and independent variables. Dependent variables were breastfeeding initiation immediately, within 24 hours and after 24 hours. Independent variables were demographic factors, healthcare utilisation and husband's controlling and violent behaviour. Multivariate logistic regressions were calculated to study the potential association between time of initiation of breastfeeding and subjects' demographic status, healthcare utilisation and husband's controlling behaviour and violence behaviour. Data were analysed using IBM SPSS. Two separate multivariate logistic regression analyses were run for two dependent variables: breastfeeding initiation within one hour (immediately) or not and within 24 hours or not. A significant level at p < 0.05 was employed in the analyses.

\subsection{Ethical Issues}

Informed consent was obtained from the participants prior to starting the survey, and the right to withdraw was emphasized throughout the survey. Ethical approval for the survey was obtained from the Institutional Review Board of Opinion Research Corporation (ORC), Macro International Incorporated, who was the main technical support provider for the whole survey.

\section{RESULTS}

Of the total amount of women participating in the study ( $\mathrm{n}=35,795)$, 39\% of them lived in urban areas and $61 \%$ in rural areas. The level of education differed between the responding women with $38 \%$ of all women having no education, $14 \%$ having primary education, 
$39 \%$ secondary education and only $9 \%$ higher education. A majority of women were Hindu (74\%) and the remaining women were either Muslim (13\%) or belonging to other religion (13\%). Most women either belonged to other backward class (34\%) or general (32\%), a minority of the women belonged to a scheduled caste $(18 \%)$ or scheduled tribe (16\%). Among all 35,795 women in the study, a total of $31.1 \%$ initiated breastfeeding within one hour and $68.6 \%$ initiated breastfeeding within first week.

\subsection{Demographics}

As seen in Table 1, women belonging to age groups 35 - 39 and 45 - 49 reported highest percentage of initiation of breastfeeding within one hour, 32.5\% respectively $32.7 \%$. The youngest women, belonging to age group 15 - 19, reported lowest percentage of initiation of breastfeeding within the first hour, $25.3 \%$.

Of women belonging to a scheduled tribe $44.8 \%$ reported initiation of breastfeeding within one hour compared scheduled caste $26.8 \%$, OBC $25.8 \%$ and finally general $31.6 \%$. Regarding breastfeeding initiation after 24 hours $41.8 \%$ of women in the scheduled caste reported doing so and $42.7 \%$ of women belonging to OBC compared to $32.5 \%$ of general women and $22.9 \%$ of women belonging to a scheduled tribe. Scheduled caste women were less likely to initiate breastfeeding within one hour ( $\mathrm{OR}=0.86, \mathrm{CI}=0.77-0.96)$ as well as within 24 hours $(\mathrm{OR}=0.86, \mathrm{CI}=0.77-0.96)$ compared to general. Same goes for other backward class, results showed that the women belonging to this class were less likely to initiate breastfeeding within one hour $(\mathrm{OR}=0.77, \mathrm{CI}=$ $0.71-0.84)$ and within 24 hours $(\mathrm{OR}=0.79, \mathrm{CI}=0.72$ 0.87 ) than women belonging to general. Furthermore, women belonging to a scheduled tribe were 1.57 times more likely to initiate breastfeeding within the first hour and almost twice as likely $(\mathrm{OR}=1.82, \mathrm{CI}=1.61-2.06)$ to initiate breastfeeding within 24 hours compared to general (Table 1).

In regard of educational level, $22.7 \%$ of women with no education initiated breastfeeding within one hour, $29.1 \%$ within 24 hours and $48.1 \%$ after 24 hours. Of women with primary education $33.2 \%$ initiated breastfeeding within one hour, $33.5 \%$ within 24 hours and $33.3 \%$ after 24 hours. Of women with secondary education $37.9 \%$ started breastfeeding within one hour, 35.9\% within 24 hours and $26.2 \%$ after 24 hours. Of all women with higher education $37.1 \%$ of them stated initiation of breastfeeding within one hour, 37.2\% within 24 hours and $25.7 \%$ after 24 hours. Women without education were less likely to initiate breastfeeding within one hour $(\mathrm{OR}=0.54, \mathrm{CI}=0.45-0.64)$ and within 24 hours $(\mathrm{OR}=$ $0.58, \mathrm{CI}=0.48-0.71$ ) compared to women with higher education. Difference was also noted between primary educational level and higher educational level, where women with primary education were less likely $(\mathrm{OR}=$ 0.73 , CI $=0.60-0.87$ ) to initiate breastfeeding within one hour, no significant results were obtained for initiation within 24 hours.

The results demonstrated that $22.8 \%$ of the poorest women initiated breastfeeding within one hour and 29\% initiated within 24 hours and 48.2\% initiated after 24 hours. The richest women however initiated breastfeeding within one hour more often (34.2\%) and 37.5\% after 24 hours and $28.3 \%$ after 24 hours. Poorest women were less likely to initiate early breastfeeding compared to richest women. However, women belonging to the second lowest wealth index (poorer) were more likely to initiated breastfeeding within one hour $(\mathrm{OR}=1.25, \mathrm{CI}=$ 1.07 - 1.45) compared to the richest women. Same results can be seen for middle income women, women in this category were even more likely to initiate breastfeeding within the first hour $(\mathrm{OR}=1.35, \mathrm{CI}=1.18-1.54)$ compared to the richest women.

There were differences in time of breastfeeding depending on how many children the women ever gave birth to. Compared to four children or more, women with three children or less were more likely to initiate breastfeeding early. Women with only one child were most likely to initiate breastfeeding within one hour $(\mathrm{OR}=$ $1.24, \mathrm{CI}=1.12-1.36)$ as well as within 24 hours $(\mathrm{OR}=$ 1.38 , CI $=1.24-1.52$ ) compared to women with four children or more. More women living in urban areas started breastfeeding within one hour (33.3\%) than women living in rural areas (30.1\%). Urban women were less likely to initiate breastfeeding both within one hour $(\mathrm{OR}=0.85, \mathrm{CI}=0.78-0.93)$ and within 24 hours $(\mathrm{OR}=$ $0.84, \mathrm{CI}=0.76-0.91)$ compared to rural women.

\subsection{Health Care Utilisation Related Issues}

More women who delivered their child in a public hospital initiated breastfeeding within one hour (41\%) than women delivering in private hospital (32.5\%) and home delivery (26.2\%). Similarly, less women who delivered their child in a public hospital initiated breastfeeding after 24 hours (19.7\%) than delivery in a private hospital (31.5\%) and home delivery (45\%). These results were also demonstrated with multiple regression where women who gave birth in a private hospital were less likely to initiate breastfeeding compared to public hospital as well as at home. The results demonstrated that women who gave birth in a private hospital were 0.67 $(\mathrm{CI}=0.57-0.79)$ times less likely to initiate breastfeeding compared to when giving birth at home. Furthermore, the likelihood of initiating breastfeeding within 24 hours increased $(\mathrm{OR}=1.63, \mathrm{CI}=1.39-1.92)$ when giving birth in a public hospital compared to at home (Table 2).

When it comes to prenatal visits, $36.6 \%$ of women who visited a doctor before birth started breastfeeding 
Table 1. Respondent's demographics and their time of breastfeeding initiation.

\begin{tabular}{|c|c|c|c|c|c|c|c|c|}
\hline \multirow{2}{*}{ Variable } & \multicolumn{2}{|c|}{ Immediately } & \multicolumn{2}{|c|}{ Within 24 hours } & \multicolumn{2}{|c|}{ After 24 hours } & \multirow{2}{*}{\begin{tabular}{c|} 
Total \\
$\mathbf{N}$
\end{tabular}} & \multirow{2}{*}{ P-values } \\
\hline & $\mathbf{N}$ & $\%$ & $\mathbf{N}$ & $\%$ & $\mathbf{N}$ & $\%$ & & \\
\hline Age & & & & & & & & $<0.001$ \\
\hline 15 - 19 years & 529 & 25.3 & 645 & 30.8 & 921 & 44.0 & 2095 & \\
\hline $20-24$ years & 3326 & 30.3 & 3700 & 33.7 & 3937 & 35.9 & 10,963 & \\
\hline 25 - 29 years & 3880 & 32.0 & 4114 & 34.0 & 4116 & 34.0 & 12,110 & \\
\hline 30 - 34 years & 2240 & 32.0 & 2221 & 34.0 & 2306 & 34.0 & 6767 & \\
\hline 35 - 39 years & 918 & 32.5 & 849 & 30.1 & 1057 & 37.4 & 2824 & \\
\hline 40 - 44 years & 261 & 31.5 & 257 & 31.0 & 310 & 37.4 & 828 & \\
\hline 45 - 49 years & 68 & 32.7 & 60 & 28.8 & 80 & 38.5 & 208 & \\
\hline Place of residence & & & & & & & & $<0.001$ \\
\hline Urban & 4689 & 33.3 & 4914 & 34.9 & 4488 & 31.9 & 14091 & \\
\hline Rural & 6533 & 30.1 & 6932 & 31.9 & 8239 & 38.0 & 21704 & \\
\hline Educational level & & & & & & & & $<0.001$ \\
\hline No education & 3108 & 22.7 & 3986 & 29.1 & 6587 & 48.1 & 13,681 & \\
\hline Primary & 1693 & 33.2 & 1713 & 33.5 & 1700 & 33.3 & 5106 & \\
\hline Secondary & 5232 & 37.9 & 4958 & 35.9 & 3617 & 26.2 & 13,807 & \\
\hline Higher & 1188 & 37.1 & 1189 & 37.2 & 823 & 25.7 & 3200 & \\
\hline Religion & & & & & & & & $<0.05$ \\
\hline Hindu & 5276 & 34.3 & 5189 & 33.7 & 4921 & 32.0 & 15,386 & \\
\hline Muslim & 893 & 33.5 & 909 & 34.1 & 867 & 32.5 & 2669 & \\
\hline Other & 929 & 32.8 & 1045 & 36.9 & 860 & 30.3 & 2834 & \\
\hline Type of caste or tribe & & & & & & & & $<0.001$ \\
\hline Scheduled caste & 1642 & 26.8 & 1925 & 31.4 & 2567 & 41.8 & 6134 & \\
\hline Scheduled tribe & 2509 & 44.8 & 1815 & 32.4 & 1281 & 22.9 & 5605 & \\
\hline $\mathrm{OBC}^{1}$ & 2983 & 25.8 & 3631 & 31.5 & 4931 & 42.7 & 11,545 & \\
\hline General & 3503 & 31.6 & 3975 & 35.9 & 3597 & 32.5 & 11,075 & \\
\hline Economic status & & & & & & & & $<0.001$ \\
\hline Poorest & 1366 & 22.8 & 1740 & 29.0 & 2890 & 48.2 & 5996 & \\
\hline Poorer & 1825 & 29.0 & 1797 & 28.6 & 2670 & 42.4 & 6292 & \\
\hline Middle & 2479 & 34.3 & 2309 & 32.0 & 2429 & 33.7 & 7217 & \\
\hline Richer & 2679 & 34.0 & 2847 & 36.1 & 2365 & 30.0 & 7891 & \\
\hline Richest & 2873 & 34.2 & 3153 & 37.5 & 2373 & 28.3 & 8399 & \\
\hline Total children ever born & & & & & & & & $<0.001$ \\
\hline 1 child & 3174 & 31.6 & 3408 & $34.0 \%$ & 3448 & $34.4 \%$ & 10,030 & \\
\hline 2 children & 3745 & $35.1 \%$ & 3806 & $35.7 \%$ & 3104 & $29.1 \%$ & 10,655 & \\
\hline 3 children & 1972 & $32.1 \%$ & 2076 & $33.8 \%$ & 2103 & $34.2 \%$ & 6151 & \\
\hline 4 or more children & 2331 & $26.0 \%$ & 2556 & $28.5 \%$ & 4072 & $45.5 \%$ & 8959 & \\
\hline
\end{tabular}

${ }^{1} \mathrm{OBC}=$ Other backward class. 
Table 2. Health care related issues and time of breastfeeding initiation.

\begin{tabular}{|c|c|c|c|c|c|c|c|c|}
\hline \multirow{2}{*}{ Variable } & \multicolumn{2}{|c|}{ Immediately } & \multicolumn{2}{|c|}{ Within 24 hours } & \multicolumn{2}{|c|}{ After 24 hours } & \multirow{2}{*}{$\begin{array}{c}\text { Total } \\
\mathbf{N}\end{array}$} & \multirow{2}{*}{ P value } \\
\hline & $\mathbf{N}$ & $\%$ & $\mathbf{N}$ & $\%$ & $\mathbf{N}$ & $\%$ & & \\
\hline Place of delivery & & & & & & & & $<0.001$ \\
\hline Home delivery & 4875 & 26.2 & 5355 & 28.8 & 8354 & 45.0 & 18,584 & \\
\hline Public hospital & 3637 & 41.0 & 3480 & 39.3 & 1746 & 19.7 & 8863 & \\
\hline Private hospital & 2710 & 32.5 & 3011 & 36.1 & 2627 & 31.5 & 8348 & \\
\hline Prenatal visit: by doctor & & & & & & & & $<0.001$ \\
\hline No & 3342 & 23.4 & 4138 & 29.0 & 6779 & 47.5 & 14,259 & \\
\hline Yes & 7878 & 36.6 & 7704 & 35.8 & 5947 & 27.6 & 21,529 & \\
\hline By ANM/nurse/midwife/LHV & & & & & & & & $<0.001$ \\
\hline No & 8222 & 32.8 & 8213 & 32.8 & 8622 & 34.4 & 25,057 & \\
\hline Yes & 2998 & 27.9 & 3629 & 33.8 & 4104 & 38.2 & 10,731 & \\
\hline By TBA/ICDS/health person & & & & & & & & $<0.001$ \\
\hline No & 10,463 & 31.6 & 10,855 & 32.8 & 11,794 & 35.6 & 33,112 & \\
\hline Yes & 757 & 28.3 & 987 & 36.9 & 932 & 34.8 & 2676 & \\
\hline Assistance: by doctor & & & & & & & & $<0.001$ \\
\hline No & 5326 & 26.9 & 5919 & 29.9 & 8553 & 43.2 & 19,798 & \\
\hline Yes & 5892 & 36.9 & 5924 & 37.1 & 4172 & 26.1 & 15,988 & \\
\hline By ANM/nurse/midwife/LHV & & & & & & & & $<0.001$ \\
\hline No & 7188 & 29.8 & 7418 & 30.7 & 9530 & 39.5 & 24,136 & \\
\hline Yes & 4030 & 34.6 & 4425 & 38.0 & 3195 & 27.4 & 11,650 & \\
\hline By TBA/Health person & & & & & & & & $<0.001$ \\
\hline No & 8581 & 36.0 & 8156 & 34.3 & 7072 & 29.7 & 23,809 & \\
\hline Yes & 2637 & 22.0 & 3687 & 30.8 & 5653 & 47.2 & 11,977 & \\
\hline By relative/friend & & & & & & & & $<0.001$ \\
\hline No & 7811 & 33.8 & 8203 & 35.5 & 7090 & 30.7 & 23,104 & \\
\hline Yes & 3407 & 26.9 & 3640 & 28.7 & 5635 & 44.4 & 12,682 & \\
\hline
\end{tabular}

ANM = Auxiliary nurse midwife; LHV = lady health visitor; TBA = Traditional Birth Attendant.

within one hour compared to $23.4 \%$ who did not visit a doctor. Of the women who did not see a doctor before birth $47.5 \%$ of them initiated breastfeeding after 24 hours. The findings of the multiple regression showed that women who had prenatal assessment by a doctor were $1.4(\mathrm{CI}=1.27$ - 1.54) times more likely to initiate breastfeeding within one hour as well as within 24 hours (OR = $1.40, \mathrm{CI}=1.27$ - 1.54) compared to women not seeing a doctor. However, women who received a prenatal assessment by another health professional than a doctor, such as traditional birth attendant or personnel related to the integrated child development services, were only more likely to initiate breastfeeding within 24 hours (OR
$=1.27, \mathrm{CI}=1.11-1.45)$ compared to women who did not receive this assessment. Furthermore, the findings demonstrated a difference between types of assistance during delivery. Women who received assistance by a nurse or midwife were less likely to initiate breastfeeding compared to women who did not get this assistance. Similar results were demonstrated for assistance by relative or a friend. Also, assistance during delivery of other personnel, such as traditional birth attendant or personnel related to the integrated child development services, were women who received such assistance were 0.57 (CI $=0.51-0.63$ ) times less likely to initiate breastfeeding within one hour and $0.67(\mathrm{CI}=0.61-0.75)$ times less 
likely within 24 hours compared to women who did not receive that assistance.

\subsection{Husband's Controlling and Violent Behavior}

Of women reporting that their husband tries to limit their contact with the family $25.3 \%$ initiating breastfeeding within one hour compared to $32.8 \%$ of women who reported no such limitations from husband. Of women experiencing sexual violence, $24.9 \%$ initiating breastfeeding within one hour compared to $32.9 \%$ of women who did not report sexual violence (Table 3).

Women who reported their husband does not trust them with money, $27.4 \%$ of them initiated breastfeeding within one hour compared to $33.1 \%$ of women who did not report such matter. It was demonstrated with multiple regression that woman who had husband that did trust her with money was more likely to initiate breastfeeding within one hour $(\mathrm{OR}=1.28, \mathrm{CI}=1.14-1.44)$ compared to woman whose husband did not trust her with money. Similarly, women who had husbands that did get jealous when they talked with other men were more likely to initiate breastfeeding within both 1 hour $(\mathrm{OR}=1.21$, CI $=1.10-1.34)$ and 24 hours $(\mathrm{OR}=1.29$, $\mathrm{CI}=1.17$ 1.41).

Table 4 describes adjusted odds ratios (ORs), confi-

Table 3. Husband's/partner's controlling and violent behaviour as predictor of time of breastfeeding initiation.

\begin{tabular}{|c|c|c|c|c|c|c|c|c|}
\hline \multirow{2}{*}{ Variable } & \multicolumn{2}{|c|}{ Immediately } & \multicolumn{2}{|c|}{ Within 24 hours } & \multicolumn{2}{|c|}{ After 24 hours } & \multirow{2}{*}{$\begin{array}{c}\text { Total } \\
\mathbf{N}\end{array}$} & \multirow{2}{*}{ P value } \\
\hline & $\mathbf{N}$ & $\%$ & $\mathbf{N}$ & $\%$ & $\mathbf{N}$ & $\%$ & & \\
\hline Husband jealous if talking with other men & & & & & & & & $<0.001$ \\
\hline No & 7167 & 33.8 & 7083 & 33.4 & 6953 & 32.8 & 21,203 & \\
\hline Yes & 1856 & 27.1 & 2150 & 31.4 & 2847 & 41.5 & 6853 & \\
\hline No & 8411 & 32.4 & 8558 & 32.9 & 9010 & 34.7 & 25,979 & \\
\hline Yes & 611 & 29.5 & 673 & 32.5 & 789 & 38.1 & 2073 & \\
\hline Does not permit her to meet her girl friends & & & & & & & & $<0.001$ \\
\hline No & 7914 & 32.9 & 7851 & 32.6 & 8300 & 34.5 & 24,065 & \\
\hline Husband tries to limit her contact with family & & & & & & & & $<0.001$ \\
\hline No & 8386 & 32.8 & 8351 & 32.7 & 8810 & 34.5 & 25,547 & \\
\hline Yes & 632 & 25.3 & 880 & 35.2 & 989 & 39.5 & 2501 & \\
\hline Husband insists on knowing where she is & & & & & & & & $<0.01$ \\
\hline No & 7885 & 32.3 & 7937 & 32.6 & 8554 & 35.1 & 24,376 & \\
\hline Yes & 1136 & 30.9 & 1293 & 35.2 & 1244 & 33.9 & 3673 & \\
\hline Husband doesn't trust her with money & & & & & & & & $<0.001$ \\
\hline No & 7749 & 33.1 & 7609 & 32.5 & 8043 & 34.4 & 23,401 & \\
\hline Yes & 1272 & 27.4 & 1620 & 34.9 & 1756 & 37.8 & 4648 & \\
\hline Yes & 1084 & 28.0 & 1250 & 32.3 & 1540 & 39.8 & 3874 & \\
\hline Experienced physical violence & & & & & & & & $<0.001$ \\
\hline No & 6524 & 34.3 & 6504 & 34.2 & 6001 & 31.5 & 19,029 & \\
\hline Yes & 2498 & 27.7 & 2725 & 30.2 & 3795 & 42.1 & 9018 & \\
\hline Experienced any sexual violence & & & & & & & & $<0.001$ \\
\hline No & 8388 & 32.9 & 8389 & 32.9 & 8724 & 34.2 & 21,203 & \\
\hline Yes & 636 & 24.9 & 844 & 33.0 & 1074 & 42.1 & 6853 & \\
\hline
\end{tabular}


Table 4. Multivariate logistic regression predicting timing of breastfeeding initiation by demographics, healthcare utilisation and husband's controlling and violent behaviour (only significant results are presented).

\begin{tabular}{ccc}
\hline \multirow{2}{*}{ Variable } & $\begin{array}{c}\text { Initiation within } \\
\mathbf{1} \text { hour }\end{array}$ & $\begin{array}{c}\text { Initiation within } \\
\mathbf{2 4} \text { hours }\end{array}$ \\
\cline { 2 - 3 } & OR $(95 \% \mathrm{CI})$ & OR $(95 \% \mathrm{CI})$ \\
\hline Economic status & & \\
Poorest & $0.88(0.74-1.05)$ & $0.76(0.63-0.90)^{* *}$ \\
Poorer & $1.25(1.07-1.45)^{* * *}$ & $0.94(0.80-1.10)$ \\
Middle & $1.35(1.18-1.54)^{*}$ & $1.08(0.94-1.25)$ \\
Richer & $1.10(0.97-1.24)$ & $1.13(0.99-1.28)$ \\
Richest & 1.0 & 1.0
\end{tabular}

Type of caste or tribe

Scheduled caste
Scheduled tribe
Other backward class
General
Total children
ever born
1 child
2 children
3 children

4 or more children

Education level

No education
Primary

Secondary

Higher education

Place of residence

Urban
Rural

Health care related issues

Place of delivery

Home delivery

Public hospital

1.0

1.0

Private hospital

0.97 (0.83 - 1.12)

$1.63(1.39-1.92)^{*}$

$0.67(0.57-0.79)^{*}$

$0.92(0.78-1.08)$

Prenatal: by doctor
No
1.0
1.0
Yes
$1.40(1.27-1.54)^{*}$

\section{Continued}

\begin{tabular}{|c|c|c|}
\hline $\begin{array}{l}\text { By TBA/ICDS/ } \\
\text { health person }\end{array}$ & & \\
\hline No & 1.0 & 1.0 \\
\hline Yes & $0.88(0.76-1.02)$ & $1.27(1.11-1.45)^{* *}$ \\
\hline \multicolumn{3}{|c|}{$\begin{array}{l}\text { Assistance: by ANM/ } \\
\text { nurse/midwife/LHV }\end{array}$} \\
\hline No & 1.0 & 1.0 \\
\hline Yes & $0.84(0.76-0.91)^{*}$ & $0.95(0.86-1.05)$ \\
\hline \multicolumn{3}{|l|}{$\begin{array}{l}\text { By TBA/ICDS/ } \\
\text { health person }\end{array}$} \\
\hline No & 1.0 & 1.0 \\
\hline Yes & $0.57(0.51-0.63)^{*}$ & $0.67(0.61-0.75)^{*}$ \\
\hline
\end{tabular}

\section{By relative/friend}

$\begin{array}{ccc}\text { No } & 1.0 & 1.0 \\ \text { Yes } & 0.75(0.68-0.82)^{*} & 0.80(0.73-0.87)^{*} \\ \begin{array}{c}\text { Partner controlling } \\ \text { behaviour } \\ \text { Husband doesn't trust } \\ \text { her with money }\end{array} & & \\ \text { No } & 1.28(1.14-1.44)^{*} & 1.11(0.99-1.25) \\ \text { Yes } & 1.0 & 1.0 \\ \text { Husband jealous if } \\ \text { talking with other men } \\ \text { No }\end{array}$

Note: The contrast category is denoted with $\mathrm{OR}=1.0 .{ }^{*} \mathrm{p}<0.001,{ }^{* *} \mathrm{p}<$ $0.005, \stackrel{* * *}{\mathrm{p}}<0.010$.

dence interval (CI) and level of significance. Only significant results of the multivariate analyses are shown in the result.

\section{DISCUSSION}

This study has focused on factors influencing time of initiation of breastfeeding among women in India. It is evident that addressable factors such as place of delivery, prenatal visits to health care facilities and assistance during delivery have an impact on time of initiation of breastfeeding. Furthermore, educational level, economic status and belonging to a caste or a tribe are important factors influencing time of initiation of breastfeeding. The study also shows the influence of partner behaviour on initiation of breastfeeding where partners with jealous and controlling behaviour have a negative influence on time of initiation. Overall, a minority of the respondents followed WHO guidelines of initiating breastfeeding within the first hour after birth considering only 31.1\% of the 35,795 women reported doing so. 
The present study demonstrates several demographic factors contributing to time of initiation of breastfeeding. Expectedly, educational level is an important factor influencing time of initiation. The present study demonstrated that women with no education are almost 50\% less likely to start breastfeeding compared to women with higher education. Previous studies have also indicated that educational level has an important influence on breastfeeding initiation [34-38]. Although there were similarities regarding economic status in percentage of early initiation it was demonstrated that poorer women (but not poorest) and middle-income women were most likely to initiate breastfeeding within the first hour. Similar results are shown elsewhere; women with high and very low economic status tend to be less prone to breastfeed $[39,40]$. However, different country and cultural context describe different trend of breastfeeding initiation. Therefore, more country and culture dependent studies are warranted.

Although colostrum is beneficial and protects the infant against infections, there are beliefs among some older women in India that colostrum is bad for the child. This may delay initiation among Indian women. Recently, a study in Ethiopia found that 35\% of the women in their study discarded the colostrum due to belief it was bad for the child [41].

Doctors demonstrated a positive effect on initiation of breastfeeding. Surprisingly, assistance by nurses and midwifes and traditional birth attendants (TBA) did not demonstrate any effectiveness on breastfeeding initiation. Dennis [42] noted in her literature review that health professionals might have a negative influence on breastfeeding if their knowledge or advice is inaccurate or inconsistent. Unfortunately, this demonstrates noncompliance with the ten steps of successful breastfeeding where it is stated that hospital staff should support mothers to initiate breastfeeding within the first half hour of birth [43]. This finding has strong policy implication. Apart from the physicians all other health care staff in India and other low income countries must be instructed to advice their expecting-patients on benefits of early initiation of breastfeeding.

The study demonstrates a difference between place of delivery and time of initiation of breastfeeding. Women giving birth in a public hospital are more likely to early initiate breastfeeding compared to women giving birth in a private hospital. This is consistent with a study in Guatemala reporting the same finding [44]. The present study does not provide any answers as to why this was the case but it could be partly attributed to the fact that caesarean section is more common and asked for in the private hospital [45] which in turn is associated with a reduced likelihood of early initiation of breastfeeding [46,47]. For example, in Brazil there has been a rapid increase in the rate of caesarean sections where the rate is around 30\% however the number is as much as $70 \%$ in some private hospitals [48]. To be compared to WHO recommendations of a rate of $10 \%-15 \%$ [49]. In contrast to this, a study in US found that women giving birth in a private hospital where more likely to initiate breastfeeding [50]. Therefore, to explore the exact situation further studies are warranted in the Indian context.

Not surprisingly, women who did not experience controlling behaviour from their partner were more likely to initiate early breastfeeding compared to their peers who did experience such control. Husband's controlling behaviour is a significant risk factor for violence against women [25]. Violence has many negative health effects such as contraceptive use, sanity, reproductive health issues and neonatal care [24,25]. Therefore the current study has deducted that partners controlling behaviour may induce family violence, which has strong influence on early initiation of breastfeeding. Furthermore, women who are or have been exposed to controlling behaviour from a partner usually experience a sense of insecurity which in turn may influence their confidence to initiate early breastfeeding, or breastfeeding at all for that matter. This is also stated by Silverman [26] who reports that women who experience intimate partner violence are at higher risk of not initiating breastfeeding and should therefore be acknowledged and receive appropriate care and support due to this. Moreover, partner support is seen as an important facilitating factor for breastfeeding initiation [51] which one may assume is not present in the case of a controlling partner. However, research on controlling behaviour and intimate partner violence and specifically early initiation of breastfeeding is needed. Fundamentally, it is necessary to increase women's empowerment and gender equality. One important element is to prioritize girls' and women's opportunity of receiving education. It is necessary for policy makers to intensify their efforts to provide girls and women with this fundamental human right that is education.

\section{LIMITATIONS}

Due to the nature of the study being a cross-sectional design it is not possible to yield causal inference. To establish causal relationships it is necessary to undertake a longitudinal study. There is also the risk of recall bias from the responding women as they need to remember past occurrences and for example may not be able to remember the exact time of initiation of breastfeeding. Nevertheless, the study has undergone rigorous scrutiny and provides a nationally representative sample and conclusions may therefore be generalized to the entire country. 


\section{RECOMMENDATIONS}

It is important for policy makers to increase women's possibilities of delivering in hospitals and other healthcare facilities to secure a safe delivery and also increase opportunities for women to initiate early breastfeeding. It is necessary to make sure that all health professionals provide support and promote early breastfeeding initiation. For example, the ten steps to successful breastfeeding should be implemented in hospitals regardless if they are public or private. It is also evident that policy makers need to increase their efforts in providing girls and women with sufficient education. This is one of many components that are needed to progress women's empowerment and improve gender equality. Furthermore, research is warranted on partners' controlling behaviour and violence and early initiation of breastfeeding.

\section{REFERENCES}

[1] WHO (2002) The optimal duration of exclusive breastfeeding-A systematic review. World Health Organization, Geneva.

[2] American Academy of Pediatrics (2005) Breastfeeding and the use of human milk. Pediatrics, 115, 496-506. http://dx.doi.org/10.1542/peds.2004-2491

[3] Beaudry, M., Dufour, R. and Marcoux, S. (1995) Relation between infant feeding and infections during the first six months of life. The Journal of Pediatrics, 126, 191-197. http://dx.doi.org/10.1016/S0022-3476(95)70544-9

[4] Dewey, K.G., Heinig, M.J. and Nommsen-Rivers, L.A. (1995) Differences in morbidity between breast-fed and formula-fed infants. The Journal of Pediatrics, 126, 696702. http://dx.doi.org/10.1016/S0022-3476(95)70395-0

[5] Kramer, M.S., Chalmers, B., Hodnett, E.D., Sevkovskaya, Z., Dzikovich, I., Shapiro, S., Collet, J.-P., Vanilovich, I., Mezen, I., Ducruet, T., Shishko, G., Zubovich, V., Mknuik, D., Gluchanina, E., Dombrovskiy, V., Ustinovitch, A., Kot, T., Bogdanovich, N., Ovchinikova, L., Helsing, E. and Group, F.T.P.S. (2001) Promotion of breastfeeding intervention trial (PROBIT). A randomized trial in the Republic of Belarus. The Journal of the American Medical Association, 285, 413-420. http://dx.doi.org/10.1001/jama.285.4.413

[6] Gianino, P., Mastretta, E., Longo, P., Laccisaglia, A., Sartore, M., Russo, R. and Mazzaccara, A. (2002) Incidence of nosocomial rotavirus infections, symptomatic and asymptomatic, in breast-fed and non-breast-fed infants. Journal of Hospital Infection, 50, 13-17.

http://dx.doi.org/10.1053/jhin.2001.1129

[7] Aniansson, G., Alm, B., Andersson, B., Hakansson, A., Larsson, P., Nylén, O., Peterson, H., Rignér, P., Svanborg, M., Sabharwal, H. and Svanborg, C. (1994) A prospective cohort study on breast-feeding and otitis media in Swedish infants. The Pediatric Infectious Disease Journal, 13, 183-187.

http://dx.doi.org/10.1097/00006454-199403000-00003
[8] Duffy, L.C., Faden, H., Wasielewski, R., Wolf, J. and Krystofik, D. (1997) Exclusive breastfeeding protects against bacterial colonization and day care exposure to otitis media. Pediatrics, 100, E7.

http://dx.doi.org/10.1542/peds.100.4.e7

[9] Brun, J.G., Nilssen, S. and Kvale, G. (1995) Breast feeding, other reproductive factors and rheumatoid arthritis. A prospective study. Rheumatology, 34, 542-546. http://dx.doi.org/10.1093/rheumatology/34.6.542

[10] Danforth, K.N., Tworoger, S.S., Hecht, J.L., Rosner, B.A., Colditz, G.A. and Hankinson, S.E. (2007) Breastfeeding and risk of ovarian cancer in two prospective cohorts. Cancer Causes Control, 18, 517-523. http://dx.doi.org/10.1007/s10552-007-0130-2

[11] Katsouyanni, K., Lipworth, L., Trichopoulou, A., Samoli, E., Stuver, S. and Trichopoulos, D. (1996) A case-control study of lactation and cancer of the breast. British Journal of Cancer, 73, 814-818. http://dx.doi.org/10.1038/bjc.1996.143

[12] Furberg, H., Newman, B., Moorman, P. and Millikan, R. (1999) Lactation and breast cancer risk. International Journal of Epidemiology, 28, 396-402. http://dx.doi.org/10.1093/ije/28.3.396

[13] Bernier, M.O., Plu-Bureau, G., Bossard, N., Ayzac, L. and Thalabard, J.C. (2000) Breastfeeding and risk of breast cancer: A meta-analysis of published studies. Human Reproduction Update, 6, 374-386. http://dx.doi.org/10.1093/humupd/6.4.374

[14] Zheng, T., Holford, T.R., Mayne, S.T., Owens, P.H., Zhang, Y., Zhang, B., Boyle, P. and Zahm, S.H. (2001) Lactation and breast cancer risk: A case-control study in Connecticut. British Journal of Cancer, 84, 1472-1476. http://dx.doi.org/10.1054/bjoc.2001.1793

[15] Manganaro, R., Marseglia, L., Mam, C., Paolata, A., Gargano, R., Mondello, M., Puliafito, A. and Gemelli, M. (2009) Effects of hospital policies and practices on initiation and duration of breastfeeding. Child: Care, Health \& Development, 35, 106-111. http://dx.doi.org/10.1111/j.1365-2214.2008.00899.x

[16] Edmond, K.M., Zandoh, C., Quigley, M.A., AmengaEtego, S., Owusu-Agyei, S. and Kirkwood, B.R. (2006) Delayed breastfeeding initiation increases risk of neonatal mortality. Pediatrics, 117, e380-e386. http://dx.doi.org/10.1542/peds.2005-1496

[17] Mullany, L.C., Katz, J., Li, Y.M., Khatry, S.K., LeClerq, S.C., Darmstadt, G.L. and Tielsch, J.M. (2008) Breastfeeding patterns, time to initiation, and mortality risk among newborns in Southern Nepal. The Journal of $\mathrm{Nu}$ trition, 138, 599-603.

[18] WHO (2006) Neonatal and perinatal mortality: Country, regional and global estimates. World Health Organization, Geneva.

[19] IBFAN (2007) The state of the world's breastfeeding: Report card initiation of breastfeeding within 1 hour. International Baby Food Action Network Asia, Dehli.

[20] Liljestrand, J. (2000) Strategies to reduce maternal mortality worldwide. Current Opinion in Obstetrics and Gynecology, 12, 513-517.

http://dx.doi.org/10.1097/00001703-200012000-00010 
[21] Shabnam, J., Gifford, M. and Dalal, K. (2011) Socioeconomic inequalities in the use of delivery care services in Bangladesh: A comparative study between 2004 and 2007. Health, 3, 762-771.

http://dx.doi.org/10.4236/health.2011.312127

[22] Shariff, A. and Singh, G. (2002) Determinants of maternal health care utilisation in India: Evidence from a recent household survey. National Council of Applied Economic Research, New Delhi.

[23] Dalal, K. and Dawad, S. (2009) Non-utilisation of public healthcare facilities: Examining the reasons through a national study of women in India. Rural and Remote Health, 9, 1178.

[24] Emenike, E., Lawoko, S. and Dalal, K. (2008) Intimate partner violence and reproductive health of women in Kenya. International Nursing Review, 55, 97-102. http://dx.doi.org/10.1111/j.1466-7657.2007.00580.x

[25] Dalal, K., Andrews, J. and Dawad, S. (2011) Contraception use and associations with initimate partner violence among women in Bangladesh. Journal of Biosocial Science, 44, 83-94.

http://dx.doi.org/10.1017/S0021932011000307

[26] Silverman, J.G., Decker, M.R., Reed, E. and Raj, A. (2006) Intimate partner violence around the time of pregnancy: Association with breastfeeding behaviour. Journal of Women's Health, 15, 934-940. http://dx.doi.org/10.1089/jwh.2006.15.934

[27] Kendall-Tackett, K.A. (2007) Violence against women and the perinatal period. Trauma, Violence, \& Abuse, 8, 344-353. http://dx.doi.org/10.1177/1524838007304406

[28] Lau, Y. and Chan, K.S. (2007) Influence of intimate partner violence during pregnancy and early postpartum depressive symptoms on breastfeeding among Chinese women in Hong Kong. The Journal of Midwifery \& Women's Health, 52, e15-e20. http://dx.doi.org/10.1016/j.jmwh.2006.09.001

[29] Simister, J. and Makowiec, J. (2008) Domestic violence in India. Indian Journal of Gender Studies, 15, 507-518. http://dx.doi.org/10.1177/097152150801500304

[30] Boyle, M.H., Georgiades, K., Cullen, J. and Racine, Y. (2009) Community influences on intimate partner violence in India: Women's education, attitudes towards mistreatment and standards of living. Social Science \& Medicine, 69, 691-697. http://dx.doi.org/10.1016/j.socscimed.2009.06.039

[31] Jana, A.K. (2009) Interventions for promoting the initiation of breastfeeding: RHL commentary. The WHO Reproductive Health Library. World Health Organization, Geneva.

[32] International Institute for Population Sciences and Macro International (2007) National family health survey (NFHS3), 2005-06: India: Volume II. International Institute for Population Sciences and Macro International, Mumbai.

[33] Dalal, K. and Lindqvist, K. (2012) A national study of the prevalence and correlates of domestic violence among women in India. Asia-Pacific Journal of Public Health, 24, 265-277.

[34] Lande, B., Andersen, L.F., Bærug, A., Trygg, K.U., LundLarsen, K., Veierød, M.B. and Bjørneboe, G.E.A. (2003)
Infant feeding practices and associated factors in the first six months of life: The Norwegian infant nutrition survey. Acta Paediatrica, 92, 152. http://dx.doi.org/10.1111/j.1651-2227.2003.tb00519.x

[35] Aidam, B.A., Perez-Escamilla, R., Lartey, A. and Aidam, J. (2005) Factors associated with exclusive breastfeeding in Accra, Ghana. European Journal of Clinical Nutrition, 59, 789-796. http://dx.doi.org/10.1038/sj.ejcn.1602144

[36] Flacking, R., Nyqvist, K.H. and Ewald, U. (2007) Effects of socioeconomic status on breastfeeding duration in mothers of preterm and term infants. The European Journal of Public Health, 17, 579-584. http://dx.doi.org/10.1093/eurpub/ckm019

[37] Kohlhuber, M., Rebhan, B., Schwegler, U., Koletzko, B. and Fromme, H. (2008) Breastfeeding rates and duration in Germany: A Bavarian cohort study. British Journal of Nutrition, 99, 1127-1132.

http://dx.doi.org/10.1017/S0007114508864835

[38] Chudasama, R.K., Patel, P.C. and Kavishwar, A.B. (2009) Breastfeeding initiation practice and factors affecting breastfeeding in South Gujarat region of India. Internet Journal of Family Practice, 7, 2.

[39] Khassawneh, M., Khader, Y., Amarin, Z. and Alkafajei, A. (2006) Knowledge, attitude and practice of breastfeeding in the north of Jordan: A cross-sectional study. International Breastfeeding Journal, 1, 17. http://dx.doi.org/10.1186/1746-4358-1-17

[40] Doula, A. (2011) Breastfeeding and socio-ecological determinants of health.

http://anthrodoula.blogspot.se/2011/06/breastfeeding-andsocio-ecological.html

[41] Setegn, T., Gerbaba, M. and Belachew, T. (2011) Determinants of timely initiation of breastfeeding among mothers in Goba Woreda, South East Ethiopia: A cross sectional study. BMC Public Health, 11, 217-223. http://dx.doi.org/10.1186/1471-2458-11-217

[42] Dennis, C.-L. (2002) Breastfeeding initiation and duration: A 1990-2000 literature review. JOGNN, 31, 12-32. http://dx.doi.org/10.1111/j.1552-6909.2002.tb00019.x

[43] Innocenti Declaration (1990) Innocenti declaration. WHO, Unicef, Florens.

[44] Dearden, K., Altaye, M., Maza, I.D., Oliva, M.D., StoneJimenez, M., Morrow, A.L. and Burkhalte, B.R. (2002) Determinants of optimal breast-feeding in peri-urban Guatemala City, Guatemala. Revista Panamericana de Salud Pública, 12, 185-192. http://dx.doi.org/10.1590/S1020-49892002000900007

[45] Marsden, W. (2000) Choosing caesarean section. Lancet, 356, $1677-1680$. http://dx.doi.org/10.1016/S0140-6736(00)03169-X

[46] Pérez-Escamilla, R., Maulén-Radovan, I. and Dewey, K.G. (1996) The association between cesarean delivery and breast-feeding outcomes among Mexican women. American Journal of Public Health, 86, 832-836. http://dx.doi.org/10.2105/AJPH.86.6.832

[47] Rowe-Murray, H.J. and Fisher, J.R.W. (2002) Baby friendly hospital practices: Cesarean section is a persistent barrier to early initiation of breastfeeding. Birth, 29, 124131. http://dx.doi.org/10.1046/j.1523-536X.2002.00172.x 
[48] Finger, C. (2003) Caesarean section rates skyrocket in Brazil. Lancet, 362, 628. http://dx.doi.org/10.1016/S0140-6736(03)14204-3

[49] WHO (1985) Appropriate technology for birth. Lancet, 2, 436-437.

[50] Besculides, M., Grigoryan, K. and Laraque, F. (2005) Increasing breastfeeding rates in New York City, 1980-2000.
Journal of Urban Health, 82, 198-206. http://dx.doi.org/10.1093/jurban/jti044

[51] Scott, J.A., Binns, C.W., Graham, K.I. and Oddy, W.H. (2006) Temporal changes in the determinants of breastfeeding initiation. Birth, 33, 37-45. http://dx.doi.org/10.1111/j.0730-7659.2006.00072.x 